\title{
Nickel(II) complexes having Imidazol-2-ylidene-N'-phenylurea ligand in the coordination sphere - syntheses and solid state structures
}

\author{
KISHOR NAKTODE ${ }^{\mathrm{a}}$, ABHINANDA KUNDU $^{\mathrm{a}}$, SUDESHNA SAHA ${ }^{\mathrm{b}}$, HARI PADA NAYEK $^{\mathrm{b}, *}$ \\ and TARUN K PANDA ${ }^{\mathrm{a}, *}$ \\ ${ }^{a}$ Department of Chemistry, Indian Institute of Technology Hyderabad, Ordnance Factory Estate, \\ Yeddumailaram 502 205, Telangana, India \\ ${ }^{b}$ Department of Applied Chemistry, Indian School of Mines, Dhanbad, 826 004, Jharkhand, India \\ e-mail: hpnayek@yahoo.com; tpanda@iith.ac.in
}

MS received 28 March 2015; revised 6 May 2015; accepted 9 May 2015

\begin{abstract}
We report the syntheses and structural studies of two nickel(II) complexes of imidazol-2-ylidene$\mathrm{N}^{\prime}$-phenylureate ligand of composition $\left[\left\{\mathrm{Im}^{t \mathrm{Bu}} \mathrm{NCON}(\mathrm{H}) \mathrm{Ph}\right\}_{2} \mathrm{Ni}(\mathrm{acac})_{2}\right](\mathbf{1})$ and $\left[\left(\mathrm{C}_{6} \mathrm{H}_{5} \mathrm{NH}_{2}\right)_{2} \mathrm{Ni}(\mathrm{acac})_{2}\right]\left[\mathrm{Im}^{\mathrm{Mes}}\right.$ $\mathrm{NCON}(\mathrm{H}) \mathrm{Ph}]$ (2). The nickel complex 1 was readily prepared by the reaction of nickel(II) acetylacetonate $\left[\mathrm{Ni}(\mathrm{acac})_{2}\right]$ with imidazol-2-ylidene- $\mathrm{N}^{\prime}$-phenylureate ligand $\left[\operatorname{Im}^{t \mathrm{Bu}} \mathrm{NCON}(\mathrm{H}) \mathrm{Ph}\right](\mathbf{L 1})$ in THF under reflux condition for $72 \mathrm{~h}$. The nickel complex 2 was obtained by the reaction of [Ni(acac $)_{2}$ ], mesityl derivative of imidazol-2-ylidene- $\mathrm{N}^{\prime}$-phenylureate ligand $\left[\mathrm{Im}^{\mathrm{Mes}} \mathrm{NCON}(\mathrm{H}) \mathrm{Ph}\right](\mathbf{L 2})$ in the presence of aniline as base under reflux condition in THF. Both the paramagnetic complexes have been characterized by FT-IR spectroscopy and elemental analyses. Solid-state structures of both the new complexes were established by single crystal X-ray diffraction analysis. In the molecular structures of complexes $\mathbf{1}$ and $\mathbf{2}$, each nickel(II) ion is six fold coordinated and form a distorted octahedral geometry. The optical properties of both complexes have been explored. The Hirshfeld surfaces are used to view and analyze the intermolecular contacts in crystalline state for complex 2.
\end{abstract}

Keywords. Nickel(II); imidazol-2-ylidene-N'-phenylurea; hexa-coordination; chelating ligands; hydrogen bonding.

\section{Introduction}

N-heterocyclic carbenes (NHCs) have become ubiquitous and ligands derived from the $1 \mathrm{H}$-imidazole heterocycle currently play a major role in organo-transition metal and coordination chemistry ${ }^{1}$ and they are also capable of stabilizing highly reactive main group molecules. $^{2-7}$ The improved electron-donating capacity and significantly high nucleophilicity found in these carbenes are responsible to effectively stabilise a positive charge in the imidazolium ring. The analogous principle can be utilized to organic imidazolin derivatives having an exo-cyclic atom or organic moiety $\mathrm{X}$ attached at the 2-position of the N-heterocycle such that, for species such as 2-methylen-, 2-imino-, 2-oxo- and 2-thioimidazolines $\left(\mathrm{X}=\mathrm{CH}_{2}, \mathrm{NH}, \mathrm{O}, \mathrm{S}\right)$, a strong contribution from the ylidic mesomeric form $\mathbf{1 B}$ may be considered (chart 1). ${ }^{8,9}$ In recent years, Tamm and co-workers have exploited this concept to prepare novel imidazolin-2imines ( $\mathrm{ImNH}, \mathrm{X}=\mathrm{NH}$ ) that can be used for the preparation of imidazolin-2-iminato complexes of transition

*For correspondence metals and rare earth elements, and more recently, of actinide metals in order to achieve very short $\mathrm{M}-\mathrm{N}$ bonds. ${ }^{10-12}$

Lavoie et al. recently reported the preparation of urea and thio-urea derivatives imidazol-2-ylidene- $\mathrm{N}^{\prime}$-ptolylureate and imidazol-2-ylidene- $\mathrm{N}^{\prime}$-p-tolylthioureate from imidazolin-2-imines and $p$-tolyl isocyanate and isothiocyanate, respectively. ${ }^{13}$ This class of neutral polydentate ligands incorporates the imidazolin-2imine fragment in its fold. The same group also introduced these urea- and thio-urea functionalised ligands into groups 4 and 10 of transition metal chemistry in order to explore their coordination behaviours. ${ }^{13}$ Very recently, we have reported the synthesis and isolation of potassium, lithium and calcium complexes of imidazol2-ylidene-N'-phenylureate ligand. ${ }^{14}$ We have observed that in the potassium complex oxygen atom of the ureate group and the nitrogen atom from the imidazolin-2imine group were attached to the metal ion. In calcium complex, the monoanionic imidazol-2-ylidene- $\mathrm{N}^{\prime}$-phenylureate ligand displayed bi-dentate $\left(\kappa^{2}\right)$ mode of coordination through the oxygen and nitrogen atoms of the isocyanate building block, leaving the imidazolin-2imine fragment uncoordinated. A tri-dentate $\left(\kappa^{3}\right)$ mode 
<smiles>[R]c1c([R])n([R])c(=[W])n1[Y9]</smiles>

Chart 1. Mesomeric forms of imidazolin-2-iminato ligand.

of coordination from imidazol-2-ylidene- $\mathrm{N}^{\prime}$-phenylureate ligand also was observed if the substituent over the imidazol ring had been changed. However, in lithium complex, the neutral imidazol-2-ylidene- $\mathrm{N}^{\prime}$-phenylureate ligand was bound to the lithium centre in a mono-dentate fashion $\left(\kappa^{1}\right)$ through an oxygen atom of the isocyanate moiety. ${ }^{14}$ To study further the coordination behaviour we would like to report the reaction of our imidazol-2-ylidene- $\mathrm{N}^{\prime}$-phenylureate ligand system with appropriate nickel(II) precursor.

Here, we report the syntheses and solid state structures of imidazol-2-ylidene- $\mathrm{N}^{\prime}$-phenylureate ligand supported two nickel(II) complexes of composition $\left[\left\{\mathrm{Im}^{\mathrm{tBu}}\right.\right.$ $\left.\mathrm{NCON}(\mathrm{H}) \mathrm{Ph}\}_{2} \mathrm{Ni}(\mathrm{acac})_{2}\right](\mathbf{1})$ and $\left[\left(\mathrm{C}_{6} \mathrm{H}_{5} \mathrm{NH}_{2}\right)_{2} \mathrm{Ni}(\mathrm{acac})_{2}\right]$ $\left[\mathrm{Im}^{\text {mes }} \mathrm{NCON}(\mathrm{H}) \mathrm{Ph}\right](\mathbf{2})$. We also report the Hirshfeld surface calculation to view and analyse the intermolecular contacts in crystalline state for complex 2 .

\section{Experimental}

\subsection{General Information}

All manipulations involving air- and moisture-sensitive organometallic compounds were carried out under argon using the standard Schlenk technique or argon-filled glove box. THF and dioxane were dried and deoxygenated by distillation over sodium and benzophenone ketyl under argon and then distilled and dried over $\mathrm{CaH}_{2}$ prior to storing in the glove box. $\mathrm{CH}_{2} \mathrm{Cl}_{2}$ was dried with calcium hydride and phosphorus pentoxide and kept with molecular sieves. FT-IR measurement (neat) was carried out on a Bruker Alpha-P Fourier transform spectrometer. The UV - vis spectra were measured on a T90+ UV-Visible spectrophotometer. Elemental analyses were performed on a BRUKER EURO EA at the Indian Institute of Technology, Hyderabad. $N$-imidazole- $N^{\prime}$ phenylureate ligands $\mathbf{L} \mathbf{1}$ and $\mathbf{L} \mathbf{2}$ were prepared according to literature procedure. ${ }^{14}\left[\mathrm{Ni}(\mathrm{acac})_{2}\right]$ and aniline were purchased from Alfa aesar India.

\subsection{Synthesis of $\left[\left\{\operatorname{Im}^{t \mathrm{Bu}} \mathrm{NCON}(\mathrm{H}) \mathrm{Ph}\right\}_{2} \mathrm{Ni}(\mathrm{acac})_{2}\right](\mathbf{1})$}

To a THF (10 mL) solution of L1 (400 mg, $1.272 \mathrm{mmol}$ ), $\mathrm{Ni}(\mathrm{acac})_{2}(163.39 \mathrm{mg}, 0.636 \mathrm{mmol})$ was added at room temperature. The resulting reaction mixture was kept under reflux condition for 3 days. The reaction mixture was filtered over celite and the filtrate was evaporated under reduced pressure to leave a green residue. The compound 1 was re-crystallized from a mixture of dioxane and $\mathrm{CH}_{2} \mathrm{Cl}_{2}(1: 1)$ at $-4^{\circ} \mathrm{C}$. Yield $323.4 \mathrm{mg}(57 \%)$. FT-IR selected peaks $\left(\mathrm{cm}^{-1}\right)$ : $3338(\mathrm{~N}-\mathrm{H}), 3050$ (aromatic $\mathrm{CH}), 1586(\mathrm{C}=\mathrm{O}$, from ligand $\mathbf{L 1}), 1509(\mathrm{C}=\mathrm{O}$, from acac). The NMR spectrum was not obtained due to paramagnetic nature of compound $\mathbf{1}$.

Anal. Calcd. for $\mathrm{C}_{56} \mathrm{H}_{86} \mathrm{Cl}_{4} \mathrm{~N}_{8} \mathrm{NiO}_{10}$ (1231.84), C 54.60, H 7.04, N 9.10. Found, C 54.32, H 6.87, N 8.79.

\subsection{Synthesis of $\left[\left(\mathrm{C}_{6} \mathrm{H}_{5} \mathrm{NH}_{2}\right)_{2} \mathrm{Ni}(\text { acac })_{2}\right]\left[\mathrm{Im}^{\mathrm{Mes}}\right.$ $N C O N(H) P h](2)$}

To a THF (10 mL) solution of $\mathbf{L 2}(438.5 \mathrm{mg}, 1.272 \mathrm{mmol})$, $\mathrm{Ni}(\mathrm{acac})_{2}(163.39 \mathrm{mg}, 0.636 \mathrm{mmol})$ and $118.5 \mathrm{mg}(1.272$ $\mathrm{mmol}$ ) aniline was added and the resulting mixture was kept under reflux condition for 3 days. The reaction mixte was filtered over celite to remove the precipitate and the filtrate was evaporated under reduced pressure to leave a green residue. The compound $\mathbf{2}$ was re-crystallized from $\mathrm{CH}_{2} \mathrm{Cl}_{2}$ at $-4^{\circ} \mathrm{C}$. FT-IR selected peaks $\left(\mathrm{cm}^{-1}\right)$ : 3048 (aromatic $\left.\mathrm{CH}\right), 2961\left(s p^{3} \mathrm{CH}\right)$, $1553(\mathrm{C}=\mathrm{O}$, from ligand $\mathbf{L} 2), 1495(\mathrm{C}=\mathrm{O}$, from acac). Yield $409 \mathrm{mg}(70 \%)$.

Anal. calcd. for $\mathrm{C}_{78} \mathrm{H}_{88} \mathrm{~N}_{10} \mathrm{NiO}_{6}$ (1320.29), C 70.96, H 6.72, N 10.61. Found, C 70.51, H 6.33, N 10.35.

\subsection{Single-Crystal X-Ray Structure Determination and Analysis}

Single crystals of complex 1 were obtained from a solution of dioxane/ $\mathrm{CH}_{2} \mathrm{Cl}_{2}$ (1:1) while single crystals of complex 2 were obtained from concentrated solution of $\mathrm{CH}_{2} \mathrm{Cl}_{2}$ under argon atmosphere at a temperature of $-4^{\circ} \mathrm{C}$. In each case, a crystal of suitable dimensions was mounted on a CryoLoop (Hampton Research Corp.) with a layer of light mineral oil and placed in a nitrogen stream at 150(2) K. All measurements were made on an Oxford Supernova X-calibur Eos CCD detector with graphite-monochromatic $\mathrm{Cu}-\mathrm{K} \alpha(1.54184 \AA)$ radiation. Crystal data and structure refinement parameters are summarized in table 1 . The structures were solved by direct methods (SIR2004) ${ }^{15}$ and refined on $F^{2}$ using the full-matrix least-squares method; using SHELXL-97. ${ }^{16}$ Non-hydrogen atoms were anisotropically refined. $\mathrm{H}$-atoms were included in the refinement on calculated positions riding on their carrier atoms. The function minimized was $\left[\sum w\left(F \mathrm{o}^{2}-F \mathrm{c}^{2}\right)^{2}\right](w=$ $\left.1 /\left[\mathrm{s}^{2}\left(F \mathrm{o}^{2}\right)+(a \mathrm{P})^{2}+b \mathrm{P}\right]\right)$, where $\mathrm{P}=\left(\operatorname{Max}\left(F \mathrm{o}^{2}, 0\right)\right.$ $\left.+2 F \mathrm{c}^{2}\right) / 3$ with $\mathrm{s}^{2}\left(F \mathrm{o}^{2}\right)$ from counting statistics. The 
Table 1. Crystallographic details of $\left[\left\{\mathrm{Im}^{\mathrm{tBu}} \mathrm{NCON}(\mathrm{H})-\mathrm{Ph}\right\}_{2} \mathrm{Ni}(\mathrm{acac})_{2}\right](\mathbf{1})$ and $\left[\left(\mathrm{C}_{6} \mathrm{H}_{5} \mathrm{NH}_{2}\right)_{2} \mathrm{Ni}(\mathrm{acac})_{2}\right]\left[\mathrm{Im}^{\text {mes }} \mathrm{NCON}(\mathrm{H}) \mathrm{Ph}\right]$ (2).

\begin{tabular}{|c|c|c|}
\hline & 1 & 2 \\
\hline CCDC No. & 1055783 & 1055784 \\
\hline Formula & $\mathrm{C}_{56} \mathrm{H}_{86} \mathrm{Cl}_{4} \mathrm{~N}_{8} \mathrm{NiO}_{10}$ & $\mathrm{C}_{78} \mathrm{H}_{88} \mathrm{~N}_{10} \mathrm{NiO}_{6}$ \\
\hline Formula weight & 1231.84 & 1320.27 \\
\hline Crystal system & Triclinic & Triclinic \\
\hline Space group & $P-1$ & $P-1$ \\
\hline $\mathrm{a},[\AA]$ & $11.2744(5)$ & $10.2926(6)$ \\
\hline $\mathrm{b},[\AA]$ & $11.6245(5)$ & $10.8103(6)$ \\
\hline$c,[\AA]$ & $13.3452(7)$ & $16.9715(8)$ \\
\hline$\alpha\left[^{\circ}\right]$ & $108.779(4)$ & $82.716(4)$ \\
\hline$\beta,\left[^{\circ}\right]$ & $94.399(2)$ & $74.039(5)$ \\
\hline$\gamma,\left[^{\circ}\right]$ & $101.405(4)$ & $77.272(5)$ \\
\hline $\mathrm{V},\left[\AA^{3}\right]$ & $1594.70(13)$ & $9073.6(5)$ \\
\hline $\mathrm{Z}$ & 1 & 1 \\
\hline Density $\left(\mathrm{mg} / \mathrm{m}^{3}\right)$ & 1.274 & 1.241 \\
\hline $\mathrm{T},[\mathrm{K}]$ & $150(2)$ & $150(2)$ \\
\hline Radiation & $\mathrm{CuK} \alpha(\lambda=1.54184 \AA)$ & $\mathrm{CuK} \alpha(\lambda=1.54184 \AA)$ \\
\hline$\mu, \mathrm{mm}^{-1}$ & 2.407 & 0.871 \\
\hline $\mathrm{F}(000)$ & 654 & 702 \\
\hline Absorption correction & Multi-scan & Multi-scan \\
\hline Reflections collected & 10913 & 12718 \\
\hline Unique reflections & $5981\left[\mathrm{R}_{\mathrm{int}}=0.0709\right]$ & $6650\left[\mathrm{R}_{\mathrm{int}}=0.0364\right]$ \\
\hline Completeness to $\theta$ & $97.4 \%$ & $98.0 \%$ \\
\hline GOF & 1.043 & 1.025 \\
\hline Refinement method & Full-matrix least-squares on $\mathrm{F}^{2}$ & Full-matrix least-squares on $\mathrm{F}^{2}$ \\
\hline $\mathrm{R}_{1} ; \mathrm{wR}_{2}$ & $0.0953 ; 0.2589$ & $0.0520 ; 0.1214$ \\
\hline
\end{tabular}

function $R 1$ and $w R 2$ were $(\mathrm{S}\|F \mathrm{o}|-| F \mathrm{c}\|) / \mathrm{S}|F \mathrm{o}|$ and $\left[\mathrm{S} w\left(F \mathrm{O}^{2}-F \mathrm{c}^{2}\right)^{2} / \mathrm{S}\left(w F \mathrm{o}^{4}\right)\right]^{1 / 2}$ respectively. The ORTEP-3 program was used to draw the molecule. Crystallographic data (excluding structure factors) for the structures reported in this article have been deposited with the Cambridge Crystallographic Data Centre as supplementary publication nos. CCDC 1055783 (1) and 1055784 (2). Copies of the data can be obtained free of charge on application to CCDC, 12 Union Road, Cambridge CB21EZ, UK (fax: + (44)1223-336-033; email: deposit@ccdc.cam.ac.uk).

\section{Results and Discussion}

The complex $\left[\left\{\operatorname{Im}^{t \mathrm{Bu}} \mathrm{NCON}(\mathrm{H}) \mathrm{Ph}\right\}_{2} \mathrm{Ni}(\mathrm{acac})_{2}\right](\mathbf{1})$ was isolated, with a good yield, when imidazol-2-ylidene- $\mathrm{N}^{\prime}$ phenylureate ligand $\left[\mathrm{Im}^{t \mathrm{Bu}} \mathrm{NCON}(\mathrm{H}) \mathrm{Ph}\right](\mathbf{L 1})$ was treated with $\left[\mathrm{Ni}(\mathrm{acac})_{2}\right]$ in THF under reflux condition for $72 \mathrm{~h}$ (scheme 1). The compound 1 was re-crystallized from methylene dichloride. The compound $\left[\left(\mathrm{C}_{6} \mathrm{H}_{5} \mathrm{NH}_{2}\right)_{2}\right.$ $\left.\mathrm{Ni}(\operatorname{acac})_{2}\right]\left[\mathrm{Im}^{\mathrm{Mes}} \mathrm{NCON}(\mathrm{H}) \mathrm{Ph}\right]$ (2) was isolated when mesityl derivative of imidazol-2-ylidene- $\mathrm{N}^{\prime}$-phenylureate ligand $\left[\mathrm{Im}^{\mathrm{Mes}} \mathrm{NCON}(\mathrm{H}) \mathrm{Ph}\right](\mathbf{L 2})$ was charged with $[\mathrm{Ni}$ $(\mathrm{acac})_{2}$ ] in THF in the presence of two equivalents of aniline under reflux condition (scheme 2). Both the para- magnetic nickel(II) compounds $\mathbf{1}$ and $\mathbf{2}$ were characterized by combustion analysis as well as FT-IR technique. The solid-state structures of complexes $\mathbf{1}$ and $\mathbf{2}$ were established by single crystal X-ray diffraction analysis.

We anticipated that, the $\mathrm{Ni}-\mathrm{O}$ bond present in $\mathrm{Ni}(\mathrm{acac})_{2}$ undergoes cleavage to produce acetyl-acetonate anion which would de-protonate the neutral ligand L1 to afford the monoanionic form of the latter to coordinate with nickel(II) ion in bi-dentate fashion as it was observed in previous work. ${ }^{14}$ However to our surprise, it was observed that instead of $\mathrm{Ni}-\mathrm{O}$ bond cleavage, six fold coordinated nickel complex 1 is formed by $\kappa^{1}$ coordination of two $\mathbf{L 1}$ ligands, to the $\mathrm{Ni}(\mathrm{acac})_{2}$. This can be attributed to the fact that $\mathrm{NH}$ proton is not acidic enough to afford mono-anionic ligand of L1. Due to bulkiness of the ligand $\mathbf{L} \mathbf{1}$ the exocyclic nitrogen of the imidazolin-2-imine fragment is not coordinating. Instead, the more electronegative oxygen atom is coordinating, as evidenced by the low carbonyl stretching frequency in the metal complex compared to that in the free ligand L1. The FT-IR spectrum of compounds 1, exhibited a strong absorption band at $1586 \mathrm{~cm}^{-1}$ assignable to $\mathrm{C}=\mathrm{O}$ stretch. This is slightly lower than that observed for the free ligand $\mathbf{L} \mathbf{1}\left(v_{\mathrm{C}=\mathrm{O}} 1627 \mathrm{~cm}^{-1}\right)$. However, it is consistent with a neutral binding mode of 


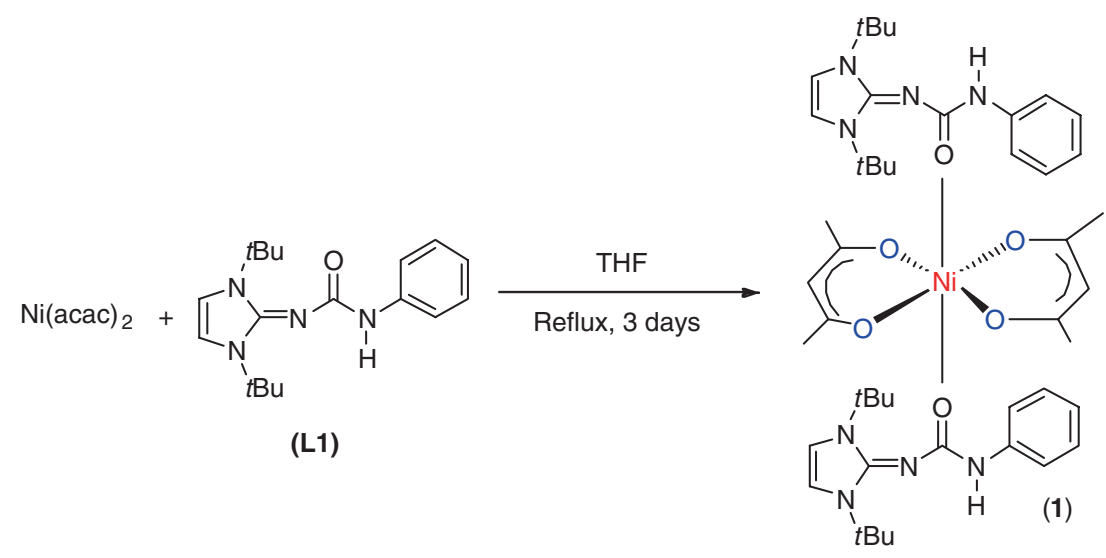

Scheme 1. Synthesis of nickel(II) complex 1.

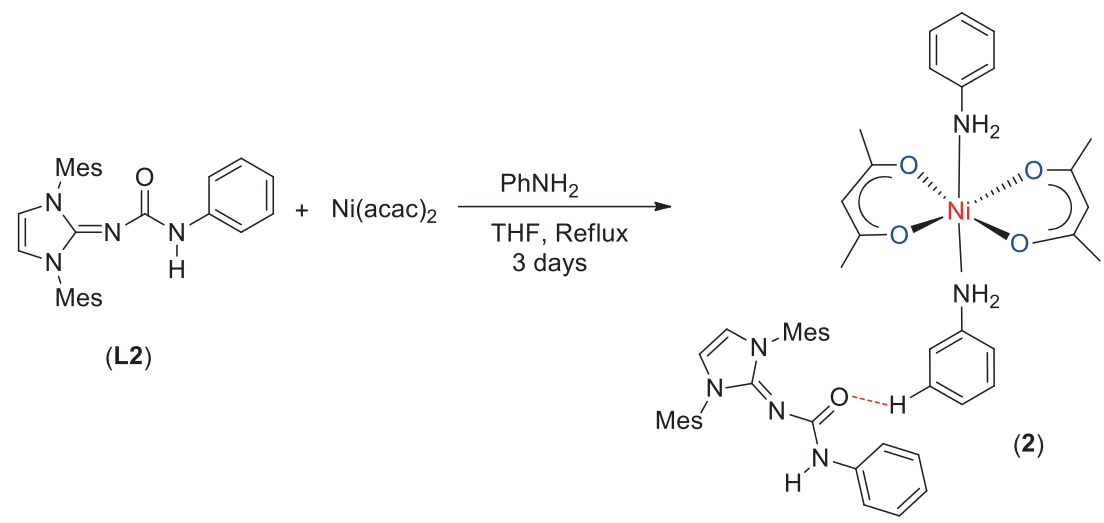

Scheme 2. Synthesis of nickel complex 2.

the ligand by oxygen lone pair. A broad N-H band was observed around $3338 \mathrm{~cm}^{-1}$, while $\mathrm{C}=\mathrm{O}$ stretching frequency was observed at $1509 \mathrm{~cm}^{-1}$ for acetylacetonate moiety. The absorption band for $\mathrm{C}=\mathrm{O}$ stretch in $\mathbf{2}$ was observed at $1553 \mathrm{~cm}^{-1}$ which is in a range similar to that $\left(1586 \mathrm{~cm}^{-1}\right)$ observed for complex $\mathbf{1}$. In addition, the carbonyl group $(\mathrm{C}=\mathrm{O})$ from acetylacetonate moiety of complex 2 shows an absorption band at $1495 \mathrm{~cm}^{-1}$ which is very close to that $\left(1509 \mathrm{~cm}^{-1}\right)$ of complex $\mathbf{1}$.

Complex 1 was re-crystallized from a mixture of $\mathrm{CH}_{2} \mathrm{Cl}_{2}$ and dioxane (1:1) and the solid-state structure of complex 1 was confirmed by single crystal X-ray diffraction analysis. The data collection parameters are given in table 1 . The complex 1 crystallizes in triclinic space group P-1 with two molecules of dioxane and one $\mathrm{CH}_{2} \mathrm{Cl}_{2}$ molecule as solvent in the unit cell. The solid state structure of the complex $\mathbf{1}$ is given in figure 1 . The coordination polyhedron of the complex $\mathbf{1}$ is formed by the chelation of four oxygen atoms of the two acetylacetonate ligands along with two oxygen atoms from the $N$-imidazole- $N^{\prime}$-phenylureate ligands. In the nickel(II) complex 1, the geometry of the central metal nickel ion can be best described as a distorted octahedron, with Ni1-O2 and Ni1-O3 distances of 2.015(2) and 1.998(2) A respectively. These Ni-O bond length values are within the same range [2.033(5) $\AA$ ] found in $\left[\mathrm{Ni}(\text { tdfnd })_{2}\left(\mathrm{O}=\mathrm{SMe}_{2}\right)_{2}\right]$ complex (tdfnd $=$ tetradecafluoro-4,6-nonandionato) reported by Carlini et $a l .{ }^{17}$ The slightly elongated Ni1-O1 distance of 2.103(2) $\AA$ compared to Ni1-O2 and Ni1-O3 indicates the coordination bond between oxygen atom from ligand $\mathbf{L} \mathbf{1}$ and the nickel ion. This observation is also similar with the $\mathrm{Ni}-\mathrm{O}$ dative bond (2.045(6) from the dimethyl formamide in complex $\left[\mathrm{Ni}(\mathrm{tdfnd})_{2}\left(\mathrm{O}=\mathrm{SMe}_{2}\right)_{2}\right]{ }^{17}$ The mean planes containing two acetylacetonate groups are parallel and have a distance of $0.134 \AA$. The nickel ion is almost coplanar and residing equidistant $(0.067 \AA)$ from both the planes. The angles O2-Ni1-O3 [92.19(9) ${ }^{\circ}$, O2-Ni1$\mathrm{O} 1\left[89.04(9)^{\circ}\right]$ indicate the octahedral geometry around nickel ion. Short interaction [NH....O2 (2.206 $\AA$ ) and NH. . .O3 (2.306 $⿱$ A)] between N-H and acetylacetonate oxygen atoms can be observed as intramolecular hydrogen bonding in complex 1. Another short interaction between carbonyl oxygen of the ligand and $\mathrm{CH}_{3}$ proton O1...H10a (2.67 ̊) are also observed. 


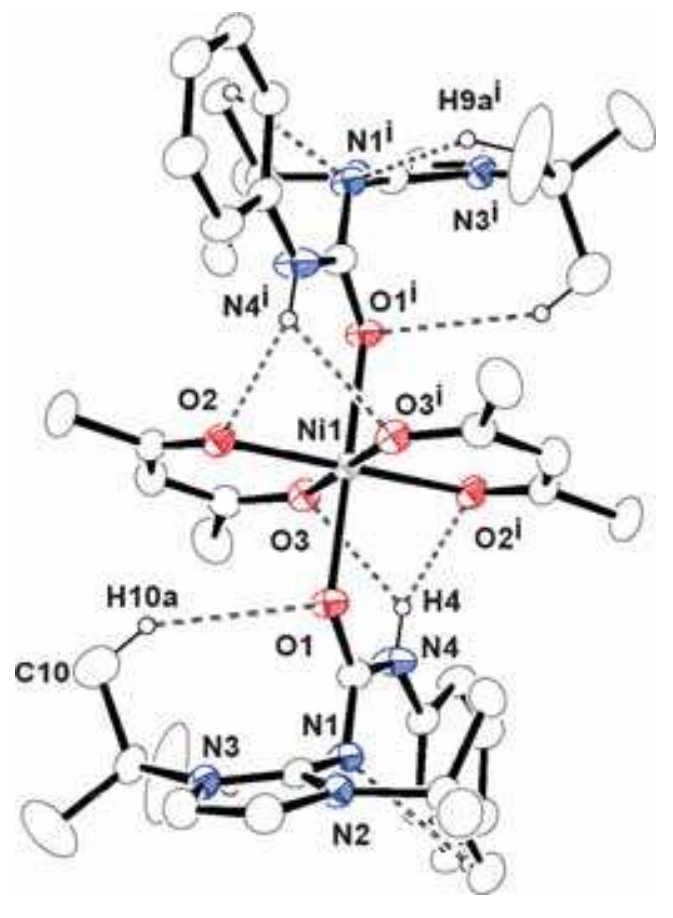

Figure 1. ORTEP diagram of $\mathbf{1}$ with thermal displacement parameters drawn at $30 \%$ probability level; hydrogen atoms are omitted for clarity (except those have $\mathrm{H}$ bonding). Selected bond distances $[\AA]$ and bond angles $\left[{ }^{\circ}\right]$ for $\mathbf{1}$ : Ni1-O3 ${ }^{\mathrm{i}} 1.998(2), \mathrm{Ni1}-\mathrm{O} 3$ 1.998(2), Ni1-O2 2.015(2), Ni1$\mathrm{O} 2^{\mathrm{i}}$ 2.015(2), Ni1-O1 ${ }^{\mathrm{i}}$ 2.103(2), Ni1-O1 2.103(2), O1-

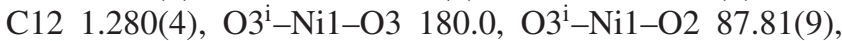

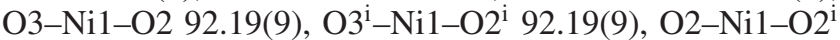
180.00(13), O $3^{\mathrm{i}}-\mathrm{Ni1}-\mathrm{O} 1^{\mathrm{i}}$ 89.96(9), O3-Ni1-O $1^{\mathrm{i}}$ 90.04(9), O2-Ni1-O1 ${ }^{\text {i }}$ 90.96(9), O3-Ni1-O1 89.96(9).

The nickel complex 2 was re-crystallized from $\mathrm{CH}_{2} \mathrm{Cl}_{2}$ and the molecular structure was determined by single crystal diffraction analysis. The complex 2 crystallizes in triclinic space group $P-1$ and the solid state structure is given in figure 2 . The coordination polyhedron of the complex $\mathbf{2}$ is formed by the chelation of four oxygen atoms of the two acetylacetonate ligands moieties along with two nitrogen atoms from two anilines. The $N$-imidazole- $N$-phenylureate ligand remained uncoordinated to the nickel presumably due to lower basicity of the -NH group compared to more basic $\mathrm{PhNH}_{2}$ ligands. In the nickel complex 2, the geometry around the nickel ion can be best described as distorted octahedron, with Ni1-O2 and Ni1-O1 of 2.007(12) and 2.023(12) $\AA$ respectively. The $\mathrm{Ni}-\mathrm{O}$ distances in $\mathbf{2}$ are in the similar range to that of complex $\mathbf{1}$. The Ni1-N1 bond length $[2.161(1) \AA]$ is slightly greater than $\mathrm{Ni}-\mathrm{N}$ bond lengths $[2.107(2) \AA]$ observed in $\left[\mathrm{NiPy}_{2}(\mathrm{NBM})_{2}\right]$ and $[2.094(2) \AA]$ found in $\left[\mathrm{Ni}(4-\mathrm{MePy})_{2}(\mathrm{NBM})_{2}\right]$ (NBM = 1-naphthoyl)benzoylmethanate) reported by Soldatov et al. ${ }^{18}$ The angles of O1-Ni1-N1 94.02(5) and $\mathrm{N} 1^{\mathrm{i}}-\mathrm{Ni} 1-\mathrm{O} 185.98(5)^{\circ}$ indicate a near orthogonal arrangement of the aniline coordination with respect to the acetylacetonate ligand towards nickel ion. Hydrogen bonding $(2.625 \AA)$ was observed between the aromatic hydrogen (H8) from one aniline moiety and $\mathrm{O} 3$ atom of the uncoordinated $N$-imidazole- $N$-phenylureate ligand.

In addition, one hydrogen atom (H1a) of the coordinated aniline molecule is hydrogen bonded with $\mathrm{O} 3$ atom of $\left[\operatorname{Im}^{t \mathrm{Bu}} \mathrm{NCON}(\mathrm{H}) \mathrm{Ph}\right]$ with a $\mathrm{H} 1 \mathrm{a} \cdots \mathrm{O} 3$ distance 2.297(1) ̊. Moreover, O2 atom is hydrogen bonded with a 1-x,1-y,1-z symmetry related hydrogen atom (H6).

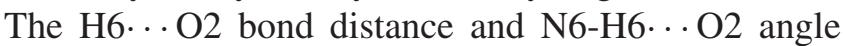
are $2.190(1) \AA$ and $168^{\circ}$ respectively. Figure 3 shows the hydrogen bonded interactions in complex 2 .

\subsection{UV-Vis spectra of nickel complexes}

UV-Visible absorption spectra of $\mathbf{L} \mathbf{1}, \mathbf{L 2}, \mathbf{1}$ and $\mathbf{2}$ were measured in $\mathrm{CH}_{2} \mathrm{Cl}_{2}$ at room temperature (figure 4) and displayed a nearly comparable absorption pattern at 230, 280, 260, $210 \mathrm{~nm}$, respectively. The UV-Vis absorption spectra for complex $\mathbf{1}$ show hyperchromic shifts compared to that of ligand $\mathbf{L} 1$ and $\mathbf{L 2}$. Compound 1 shows an absorption maxima at $\lambda_{\max }=230 \mathrm{~nm}$ due to $\pi \rightarrow \pi^{*}$ transition in addition with another peak at $\lambda_{\max }=275 \mathrm{~nm}$ due to $n \rightarrow \pi^{*}$ transition. In contrast, compound 2 shows absorption maxima at $\lambda_{\max }=$ $235 \mathrm{~nm}$ due to $\pi \rightarrow \pi^{*}$ transition along with a band at $280 \mathrm{~nm}$ for $n \rightarrow \pi^{*}$ transition. There is no strong absorption peak in 400-700 nm range for $d \rightarrow d$ transition of the nicke complexes in case of solution UVVisible spectra. However, the solid-state UV-Visible absorption spectra of $\mathbf{L 1}, \mathbf{L 2}, \mathbf{1}$ and $\mathbf{2}$ were significantly different from that of solution (figure 4). A broad absorption band from $200-400 \mathrm{~nm}$ in the solid state UV-Visible spectra of $\mathbf{L} \mathbf{1}$ and $\mathbf{L} \mathbf{2}$ were attributed to the $\pi \rightarrow \pi^{*}$ transition of ligand. In the solid state UV-Visible spectrum of complex 2 , strong absorption band for $d \rightarrow d$ transition observed at $\lambda_{\max }=550 \mathrm{~nm}$ whereas complex 1 shows hypochromic shift $\left(\lambda_{\max }=\right.$ $650 \mathrm{~nm}$ ) to that of complex 2 , due to strong ligand field splitting as nitrogen donor ligand is coordinating with nickel(II) ion.

\subsection{Hirshfeld surface analysis}

Hirshfeld surfaces are used to analyse and visualize short and long range intermolecular interactions by colour coding. Even the relative strength of these interactions can be determined from the intensity of the colour. ${ }^{19,20}$ The Hirshfeld surface analysis was performed to shed light on the hydrogen bonding interactions between $\left[\left(\mathrm{C}_{6} \mathrm{H}_{5} \mathrm{NH}_{2}\right)_{2} \mathrm{Ni}(\mathrm{acac})_{2}\right]$ and $\left[\operatorname{Im}^{\mathrm{Mes}} \mathrm{NCON}(\mathrm{H}) \mathrm{Ph}\right]$ of $\boldsymbol{2}$. 


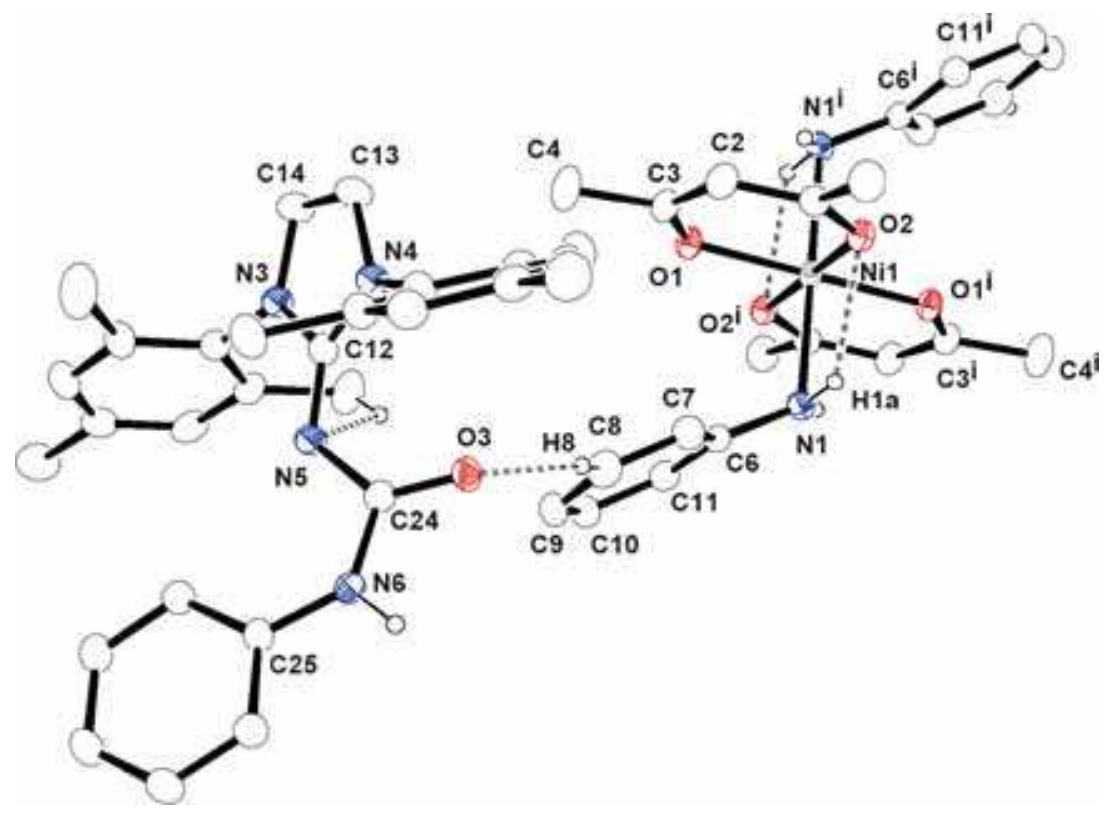

Figure 2. ORTEP diagram of $\mathbf{2}$ with thermal displacement parameters drawn at $30 \%$ probability level;. Hydrogen atoms are omitted except those have hydrogen bonding. Selected bond lengths $[\AA]$ and bond angles $\left[{ }^{\circ}\right]$ are given. $\mathrm{Ni}_{1}-\mathrm{O}^{\mathrm{i}} 1 \quad 2.007(12), \quad \mathrm{Ni} 1-\mathrm{O} 1 \quad 2.007(12), \mathrm{Ni} 1-\mathrm{O} 2 \quad 2.023(12), \quad \mathrm{Ni} 1-\mathrm{O}^{\mathrm{i}} 2$ 2.023(12), Ni1-N 1 2.160(15), Ni1-N1 2.160(15), O1-C3 1.260(2), N1-C6 1.424(2), O(1)i-Ni(1)-O(1) 180.0(5), O(1)i-Ni(1)-O(2) 88.06(5), O(1)Ni(1)-O2 91.94(5), O ${ }^{\mathrm{i} 1-N i 1-\mathrm{O}^{\mathrm{i}} 2}$ 91.94(5), O1-Ni1-O'2 88.06(5), O2-Ni1O 2 180.0, C6-N1-Ni1 119.43(11), C1-O2-Ni1 124.61(11), O1-Ni(1)-N1 94.02(5), N $\mathrm{N}^{\mathrm{i}} 1-\mathrm{Ni} 1-\mathrm{O} 1$ 85.98(5).

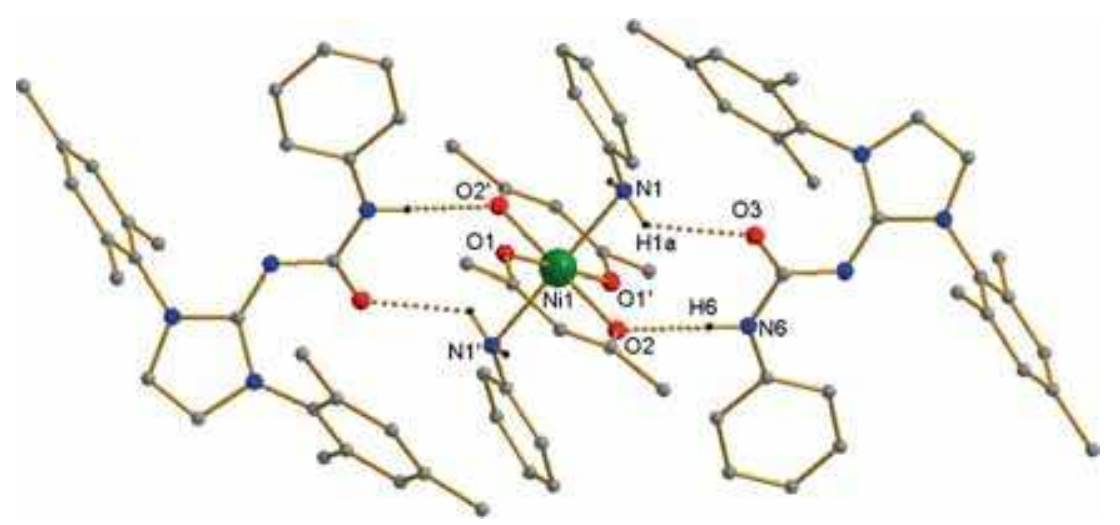

Figure 3. Hydrogen bonding interaction in $\mathbf{2}$.

The Hirshfeld surface enclosing a molecule of $\left[\left(\mathrm{C}_{6} \mathrm{H}_{5} \mathrm{NH}_{2}\right)_{2} \mathrm{Ni}(\mathrm{acac})_{2}\right]$ is calculated with respect to $\mathrm{d}_{\mathrm{e}}$, $\mathrm{d}_{\mathrm{i}}$ and $\mathrm{d}_{\text {norm }}$ using Crystal Explorer program. ${ }^{21}$ The $\mathrm{d}_{\mathrm{e}}$ and $\mathrm{d}_{\mathrm{i}}$ represents the nearest distance of external or internal nucleus from a point of interest on the iso-surface. The normalized distance $\left(d_{\text {norm }}\right)$ depends on both $d_{e}$ and $d_{i}$. Figure 5 shows the Hirshfeld surface and 2D fingerprint plots. The dominant interections between $\mathrm{H}$. . O can be seen as the bright red areas on the Hirshfeld surface. Other visible areas on the surface appeared bacuse of $\mathrm{H} \cdots \mathrm{H}$ and $\mathrm{H} \cdots \mathrm{C}$ interactions. The $2 \mathrm{D}$ fingerprint plot can be docomposed to anlyse the contribution of a particular interaction of an atom pair contact to the full fingerprint plot. The $\mathrm{H} \cdots \mathrm{O} / \mathrm{O} \cdots \mathrm{H}$ interactions consists of $9.7 \%$ of the total surface of each molecule of $\left[\left(\mathrm{C}_{6} \mathrm{H}_{5} \mathrm{NH}_{2}\right)_{2} \mathrm{Ni}(\mathrm{acac})_{2}\right]$. Contribution from other long range interactions such as $\mathrm{H} \cdots \mathrm{H} / \mathrm{H} \cdots \mathrm{H}$ and $\mathrm{H} \cdots \mathrm{C} /$ $\mathrm{C} \cdots \mathrm{H}$ are $73.6 \%$ and $14.9 \%$, respectively. No significant contrubition was found for $\mathrm{C} \cdots \mathrm{C} / \mathrm{C} \cdots \mathrm{C}$ and $\mathrm{N} \cdots \mathrm{H} / \mathrm{H} \cdots \mathrm{N}$ interactions. 

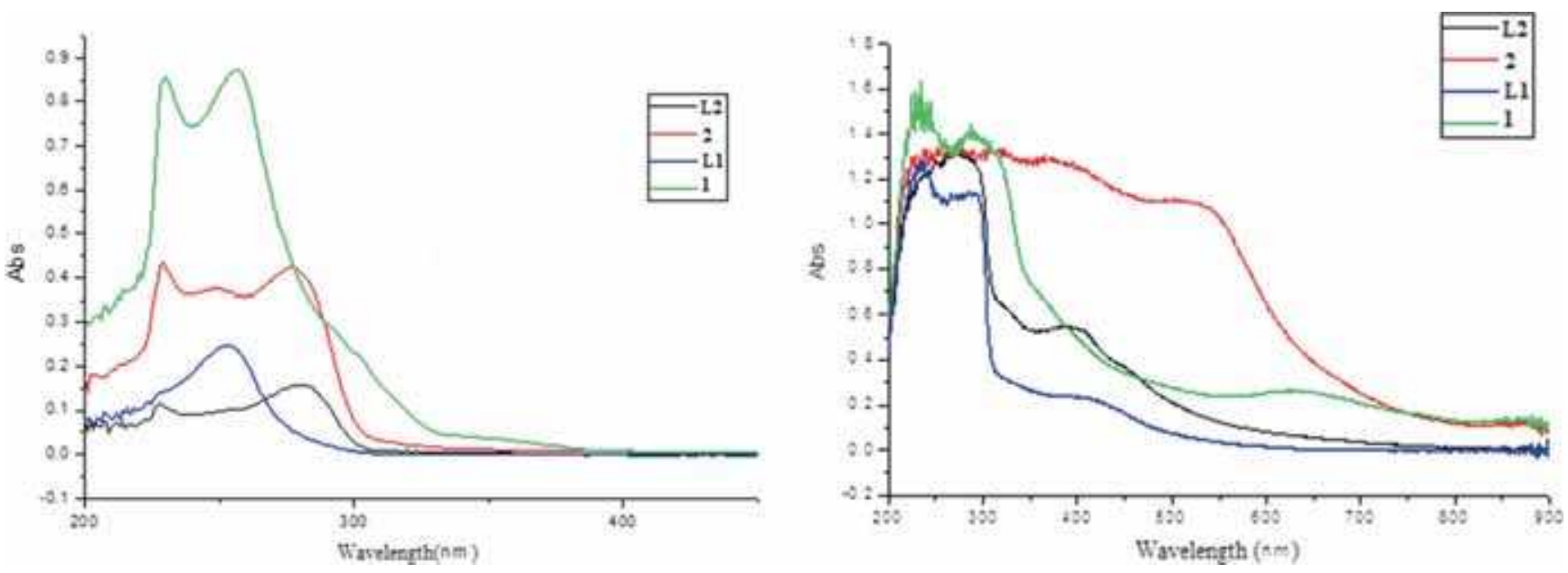

Figure 4. UV-Vis spectrum $\left(10^{-2} \mathbf{M}\right)$ of $\mathbf{L 1}, \mathbf{L} 2, \mathbf{1}$ and $\mathbf{2}$ in $\mathrm{CH}_{2} \mathrm{Cl}_{2}$ (left) and solid state UV-Vis spectrum of $\mathbf{L 1}, \mathbf{L 2}, \mathbf{1}$ and 2 (right).

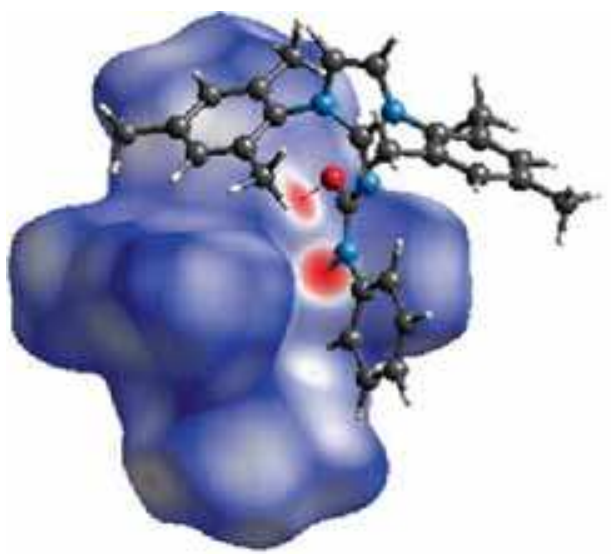

(a)

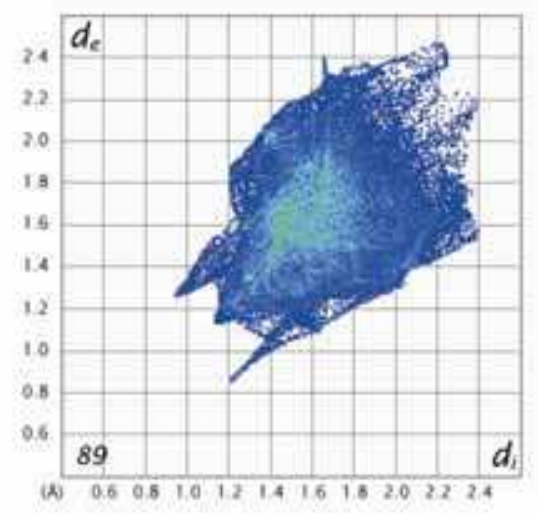

(b)

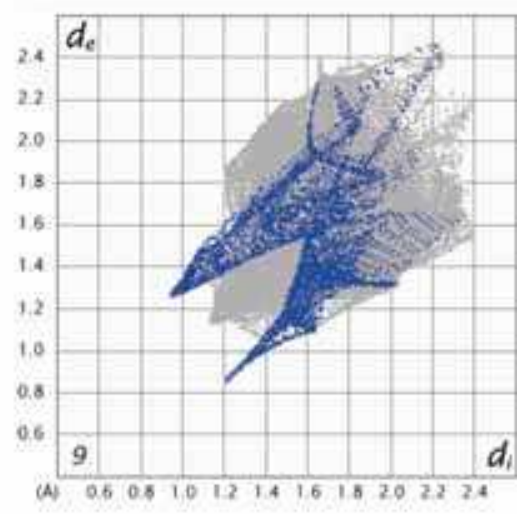

(c)

Figure 5. (a) Hirshfeld surface mapped over $\mathrm{d}_{\text {norm }}$; (b) 2D Fingerprint plot; (c) 2D fingerprint plot with the $\mathrm{O} \cdots \mathrm{H} / \mathrm{H}$. . O interactions highlighted in colour.

\section{Conclusion}

To sum up, we have reported the syntheses and solidstate structures of two imidazol-2-ylidene- $\mathrm{N}^{\prime}$-phenylureate ligand coordinated nickel(II) complexes. In the first complex 1, ligand $\mathbf{L} \mathbf{1}$ displays a $\kappa^{1}$ coordination through the coordination of carbonyl oxygen to the nickel ion which adopts an octahedral gemetry around it. In contrast, the imidazol-2-ylidene- $\mathrm{N}^{\prime}$-phenylureate ligand $\mathbf{L} \mathbf{2}$ remains uncoordinated to the nickel ion in complex 2, and the nickel ion preferred octahedral geometry by two acetylacetonato groups and two aniline ligands.

\section{Supplementary Information}

The FT-IR spectra of $\mathbf{1}$ and $\mathbf{2}$ are given in supplementary information available at www.ias.ac.in/chemsci.

\section{Acknowledgements}

This work is supported by the Science and Engineering Research Board (SERB), Department of Science and Technology (DST), India (project no. SB/S1/IC/ 045/2013). The instrumental facilities were provided by the Indian Institute of Technology Hyderabad (IITH). K.N. thanks the University Grants Commission, India for his $\mathrm{PhD}$ fellowship.

\section{References}

1. Nolan S P 2006 In N-Heterocyclic Carbenes in Synthesis (Weinheim: Wiley-VCH)

2. Wang Y and Robinson G H 2009 Chem. Commun. 5201

3. Wang Y and Robinson G H 2012 Dalton Trans. 41337

4. Martin D, Melaimi M, Soleilhavoup M and Bertrand G 2011 Organometallics 305304

5. Wang Y and Robinson G H 2011 Inorg. Chem. 5012326 
6. Yao S -L, Xiong Y and Driess M 2011 Organometallics 301748

7. Martin D, Soleilhavoup M and Bertrand G 2011 Chem. Sci. 2389

8. (a) Kuhn N, Gohner M, Frenking G, Chen Y, Gielen M, Willem R and Wrack-meyer B (Eds.) 2002 Unusual Structures and Physical Properties in Organometallic Chemistry (UK: John Wiley) p. 337; (b) Kuhn N, Gohner M, Grathwohl M, Wiehoff J, Frenking G and Chen Y 2003 Z. Anorg. Allg. Chem. 629793

9. (a) Carmalt C J and Cowley A H 2000 Adv. Inorg. Chem. 50 1; (b) Kuhn N and Al-Sheikh A 2005 Coord. Chem. Rev. 249829

10. (a) Panda $\mathrm{T} \mathrm{K}$, Randoll S, Hrib $\mathrm{C} \mathrm{G}$, Jones $\mathrm{P} \mathrm{G}$, Bannenberg T and Tamm M 2007 Chem. Commun. 5007; (b) Beer S, Brandhorst K, Grunenberg J, Hrib C G, Jones P G and Tamm M 2008 Org. Lett. 10 981; (c) Petrovic D, Hill L M R, Jones P G, Tolman W B and Tamm M 2008 Dalton Trans. 887; (d) Petrovic D, Hrib C G, Randoll S, Jones P G and Tamm M 2008 Organometallics 27 778; (e) Beer S, Brandhorst K, Hrib C G, Wu X, Haberlag B, Grunenberg J, Jones P G and Tamm M 2009 Organometallics 28 1534; (f) Panda T K, Trambitas A G, Bannenberg T, Hrib C G, Randoll S, Jones P G and Tamm M 2009 Inorg. Chem. 48 5462; (g) Trambitas A, Panda T K, Jenter J, Roesky P, Daniliuc C -G, Hrib C, Jones P G and Tamm M 2010 Inorg. Chem. 49 2435; (h) Trambitas A G, Panda T K and Tamm M 2010 Z. Anorg. Allg. Chem. 636 2156; (i) Panda T K, Hrib C G, Jones P G and Tamm M 2010 J. Organomet. Chem. 695 2768; (j) Tamm M, Trambitas A G, Hrib C and Jones P G 2010 Terrae Rarae. 7 1; (k) Trambitas A G, Melcher D, Hartenstein L, Roesky P W, Daniliuc C, Jones P G and Tamm M 2012 Inorg. Chem. 51 6753; (1) Eisen M, Karmel I, Botoshansky M and Tamm M 2014 Inorg. Chem. 53 694; (m) Wu X and Tamm M 2014 Coord. Chem. Rev. 260116

11. Glöckner A, Bannenberg T, Daniliuc C G, Jones P G and Tamm M 2012 Inorg. Chem. 514368

12. (a) Tamm M, Randoll S, Herdtweck E, Kleigrewe N, Kehr G, Erker G and Rieger B 2006 Dalton Trans. 459; (b) Beer S, Hrib C G, Jones P G, Brandhorst K, Grunenberg J and Tamm M 2007 Angew. Chem., Int. Ed. 46 8890; (c) Stelzig S H, Tamm M and Waymouth R M 2008 J. Polym. Sci., Part A: Polym. Chem. 46 6064; (d) Beer S, Brandhorst K, Grunenberg J, Hrib C G, Jones P G and Tamm M 2008 Org. Lett. 10 981; (e) Glöge T, Petrovic D, Hrib C, Jones P G and Tamm M 2009 Eur. J. Inorg. Chem. 4538; (f) Beer S, Brandhorst K, Hrib C G,
Wu X, Haberlag B, Grunenberg J, Jones P G and Tamm M 2009 Organometallics 28 1534; (g) Haberlag B, Wu X, Brandhorst K, Grunenberg J, Daniliuc C G, Jones P G and Tamm M 2010 Chem. Eur. J. 16 8868; (h) Tamm M and Wu X 2010 Chemistry Today 28 60; (i) Tamm M and Wu X 2010 Chim. Oggi. 28 10; (j) Wu X and Tamm M 2011 Beilstein J. Org. Chem. 7 82; (k) Trambitas A G, Yang J, Melcher D, Daniliuc C G, Jones P G, Xie Z and Tamm M 2011 Organometallics 30 1122; (1) Wu X and Tamm M 2011 Beilstein J. Org. Chem. 7 82; (m) Sharma M, Yameen H, Tumanskii B, Filimon S -A, Tamm M and Eisen M 2012 J. Am. Chem. Soc. 134 17234; (n) Haberlag B, Freytag M, Daniliuc C G, Jones P G and Tamm M 2012 Angew. Chem. Int. Ed. 51 13019; (o) Nomura K, Fukuda H, Apisuk W, Trambitas A, Kitiyanan B and Tamm M 2012 J. Mol. Cat. A: Chem. 363-364 501; (p) Shoken D, Sharma M, Botoshansky M, Tamm M and Eisen M S 2013 J. Am. Chem. Soc. 135 12592; (q) Lysenko S, Daniliuc C G, Jones P G and Tamm M 2013 J. Organomet. Chem. 744 7; (r) Apisuk W, Trambitas A G, Kitiyanan B, Tamm M and Nomura K 2013 J. Polym. Sci. Part A: Polym. Chem. 51 2575; (s) Volbeda J, Jones P G and Tamm M 2014 Inorg. Chim. Acta. 422 158; (t) Nomura K, Bahuleyan B, Zhang S, Sharma P V, Katao S, Igarashi A, Inagaki A and Tamm M 2014 Inorg. Chem. 53607

13. (a) Dastgir S and Lavoie G G 2010 Dalton Trans. 39 6943; (b) Dastgir S and Lavoie G G, 2012 Dalton Trans. 41 9651; (c) Harkness M B, Alvarado E, Badaj A C, Skrela B C, Fan L, and Lavoie G G 2013 Organometallics 323309

14. Naktode K, Bhattacharjee J, Nayek H P and Panda T K 2015 Dalton Trans. 447458

15. Altomare A, Burla M C, Camalli G, Cascarano G, Giacovazzo C, Gualiardi A and Polidori G 1994 J. Appl. Cryst. 27435

16. Sheldrick G M 2008 Acta Cryst. A64 112

17. Benvenuti F, Carlini C, Marchetti F, Marchionna M, Galletti A M R and Sbrana G 2001 J. Organomet. Chem. 622286

18. Soldatov D V, Enright G D, Zaninac A S and Sokolov I E 2002 J. Supramolecular Chem. 2441

19. McKinnon J J, Jayatilaka D and Spackman M A 2007 Chem. Commun. 3814

20. Spackman M A and Jayatilaka D 2009 Cryst. Eng. Comm. 1119

21. Wolff S K, Grimwood D J, McKinnon J J, Jayatilaka D and Spackman M A 2007 CrystalExplorer 2.0. University of Western Australia, Perth, Australia 